\title{
Knowledge and practice of nurses regarding tuberculosis infection control in selected tertiary hospital
}

\author{
Lakshmi Basak ${ }^{1,}{ }^{*}$, Rozina parvin ${ }^{2}$, Sharnolata Roy ${ }^{3}$ and Naznin Akter Jahan 4 \\ ${ }^{1}$ Chest Diseases Hospital, Khulna, Bangladesh. \\ 2 Upazila Health Complex, Ulipur Kurigram, Bangladesh. \\ 3 Upazila Health Complex, Modhupur. Tangail, Bangladesh. \\ ${ }^{4}$ Department of Nutrition and Biochemistry, National Institute of Preventive and Social Medicine (NIPSOM), Dhaka, \\ Bangladesh.
}

International Journal of Biological and Pharmaceutical Sciences Archive, 2022, 03(01), 048-055

Publication history: Received on 29 December 2021; revised on 07 February 2022; accepted on 09 February 2022

Article DOI: https://doi.org/10.53771/ijbpsa.2022.3.1.0024

\begin{abstract}
Tuberculosis caused by a microorganism called Mycobacterium tuberculosis. The undiagnosed or unsuspected patient with tuberculosis is the primary risk to health care workers and to the general population. The major risks for TB infection are through close contact to the infectious case before diagnosis. The objective of the study was to assess the level of knowledge and practice of nurses regarding tuberculosis infection control. This cross sectional study was conducted in Chest Diseases Hospital, Khulna and Khulna Medical College Hospital, Khulna. From 1st January to 31st December, 2020. Purposive sampling was adopted and semi-structured questionnaire was used to collect information from the respondents. Two hundred twenty-four (224) participants involve in the study. We found that the majority of the respondent's age were 31-40 years, Female 99.6\%, and 45\% were Muslim. Majority 87.1\% were senior staff nurse and $87.5 \%$ were diploma in nursing. Among the respondents $64.7 \%$ had good knowledge and $71.0 \%$ had good practice respectively. Most of the respondents $(74.1 \%, n=181)$ had no training on TBIC. Significant statistical difference was found regarding professional education and knowledge $(\mathrm{p}=.002)$. This cross-sectional study revealed a majority of the respondents were found to have good TBIC knowledge and practices. More TBIC program should be enhanced among nurses whose knowledge and practice were poor. It can also be used to benchmark the evaluation of TBIC interventions, especially in setting where TBIC guideline have not been optimally implemented. It is recommended that training on TBIC should be provided to nurses.
\end{abstract}

Keywords: Knowledge; Practice; Nurses; Tuberculosis; Infection control; Tertiary hospital

\section{Introduction}

Tuberculosis (TB) is a major global public health problem. It is caused by a microorganism called Mycobacterium tuberculosis (MTB) and commonly affects the lungs (pulmonary TB or PTB) and this accounts for about $85 \%$ of all TB cases [1]. TB can also affect other organs in the body (extra-pulmonary TB): lymph nodes, abdomen, bones and joints, pericardium, pleura and meninges; and it can also be generalized. PTB is the most important source of TB transmission as MTB is carried in air-borne droplets or aerosols produced when a person infected with PTB coughs, sneezes, spits, talks or sings. TB is preventable and there is affordable and effective treatment for it. In 2017 , an estimated 10 million new cases of TB were recorded globally, with the African region accounting for $25 \%$ of these cases; and worldwide, TB was the leading cause of death due to an infectious disease [2].

\footnotetext{
${ }^{*}$ Corresponding author: Lakshmi Basak

Chest Diseases Hospital, Khulna, Bangladesh.

Copyright (C) 2022 Author(s) retain the copyright of this article. This article is published under the terms of the Creative Commons Attribution Liscense 4.0.
} 
Tuberculosis infection control is a combination of measures aimed at minimizing the risk of TB transmission within populations. It is recommended that all health-care settings should have a TB infection control program designed to ensure prompt detection, airborne precautions, and treatment of persons who have suspected or confirmed TB disease. TBIC program should be based on a three level hierarchy of controls, including administrative, environmental, and respiratory protection. Nosocomial TB transmission, which means the spread of TB in health facilities, is an enormous challenge for healthcare workers (HCWs) worldwide. The increased risk of nosocomial TB transmission among HCWs has been well-documented and HCWs have a higher incidence of TB disease than the general population [3]. The increased exposure of HCWs to infectious TB patients, especially where there is inadequate implementation of TB infection control (TBIC) measures, accounts for the heightened risk [4]. Tuberculosis infection control is a combination of measures aimed at minimizing the risk of TB transmission within populations. It is recommended that all health-care settings should have a TB infection-control program designed to ensure prompt detection, airborne precautions, and treatment of persons who have suspected or confirmed TB disease. Such a program should be based on a three level hierarchy of controls, including administrative, environmental, and respiratory protection [5].

"The risk of transmission of M. tuberculosis from individuals with TB to other patients and to health professionals (HPs) has been recognized for many years. This risk is high in health facilities especially in man low-and middle-income countries". Tuberculosis infection control (TBIC) is a combination of measure aimed at minimizing the risk of TB infection transmission within populations [6]. Gaps in (TBIC) implementation practice predispose health professionals to nosocomial tuberculosis (TB) transmission. TBIC is not appropriately implemented in most developing countries. The aim of this study was to determine the levels of TBIC-related knowledge and practices of nurses in selected tertiary hospital and their associated socio-demographic factors. The study outcomes will contribute to the general body of knowledge on the status of implementation of TBIC measures and will provide useful baseline information for the designing of appropriate interventions to address issues related to this and for subsequent evaluation of the intervention.

\section{Material and methods}

\subsection{Study design}

Descriptive type of cross-sectional.

\subsection{Study period}

Total study period was 1 (one) year from January 2020 to December 2020.

\subsection{Study place}

Chest diseases hospital, Khulna and Khulna Medical College Hospital, Khulna, Bangladesh.

\subsection{Study population}

Nurses who are work in mentioned hospital.

\subsection{Sample size}

The sampling size was determined by the following formula. Sample size for that proposed study was calculated by the following formula-

$$
\mathrm{z}^{2} \mathrm{pq} / \mathrm{d}^{2}
$$

Here,

$\mathrm{n}=$ assumed sample size

$\mathrm{z}=$ the standard normal deviation usually set at 1.96 at $95 \%$ confidence level

$\mathrm{p}=$ the proportion in the population possessing the characteristics of interest.

$q=1-p$, here, $1-0.74=0.26$

$\mathrm{d}=$ Acceptable margin of error or precision $(5 \%)=0.05$

From the previous study, proportion of complementary feeding practices among mothers is $74 \%$; value of $\mathrm{p}=0.74$, (Saleh, F., et al., 2014). 
From the above formula the estimated sample size is 295.

*Though the actual sample size was 295 but data was collected from 224 respondents due to COVID - 19 pandemic situations.

\subsection{Inclusion Criteria}

- $\quad$ Nurses who are working in selected tertiary hospital and service more than 6 months.

- Nurses who are willing to participate.

- Nurses are available during data collection.

\subsection{Exclusion Criteria}

- Nurses who refuses to take part in the study.

- Nurses who are not available during data collection.

- Nurses who are ill during data collection.

\subsection{Sampling Technique}

Purposive sampling was used to conduct the thesis.

\subsection{Data Collection tools}

A pre-tested modified Semi-structured self-administered questionnaire was developed by using selected variables according to objectives. The questionnaire was divided into 3 sections including 1) Demographic Questionnaire, 2) Knowledge regarding tuberculosis infection control Questionnaire, 3) Practice regarding tuberculosis infection control Questionnaire.

\subsection{Data collection technique}

Face to face self-administered questionnaire. At first, purpose of the study was informed to the respondents. A complete assurance was given that all information would be kept confidentially. Informed written consent was obtained from respondents. Informed consent was documented properly. Data was collected by face to face self- administered questionnaire in Bangla. Each respondent was interviewed separately and their privacy and confidentiality was maintained strictly. The right was being given to the participants not to participate and to discontinue participation at any time in study with consideration/without penalty. Their participation and contribution was acknowledging with due respects.

\subsection{Data management and analysis plan}

At the end of the day of data collection, from individual questionnaire is edit through checking and rechecking to see whether it is fill completely and consistently. An analysis process will be developed to keep in view with the objectives of the study. All the data is entering and analyze by using Statistical Packages for Social Science (SPSS) software version 25.

\subsection{Measurement}

Knowledge was assessed by 10 questions focusing on cause, micro-organism, identify, types, spread, opportunistic infection, separated tuberculosis patients. Giving correct answer earned score of 1 if not score 0 . Knowledge was categorized into good and poor. Practice was assessed by 22 questions and 9 observational checklists. Giving correct answer earned score of 1 if not score 0 . Using cut-off points of 80 and $100 \%$ for good knowledge and practice scores respectively.

\subsection{Ethical implication}

All the information collected for the study was utilized only for the purpose of thesis and was not disclosed to anyone. At the beginning, approval was obtained from the ethical committee of NIPSOM, under the Bangabandhu Sheikh Mujib Medical University, Dhaka, Bangladesh. Before collection of data, written permission was taken from the Director of the hospital. Also written permission was taken from the respondents. A complete assurance was given that all information keeps confidentially. Their participation and contribution was acknowledge with due respects. The right was being given to the respondents not to participate and to discontinue participation at any time in study with consideration/without penalty. Informed consent will be documented properly. Each respondent was interviewed 
separately and their privacy and confidentiality was maintained strictly. Outcome of the study would be public health importance.

\section{Limitations of the Study}

- This is a cross sectional study.

- May have the chance to bias

\section{Results}

Table 1 Distribution of the respondents according to Socio demographic characteristics $(n=224)$

\begin{tabular}{|c|c|c|c|}
\hline Variable's & Characteristics & Number & Percent \\
\hline \multirow[t]{4}{*}{ Age } & $21-30$ years & 71 & 31.7 \\
\hline & $31-40$ years & 93 & 41.5 \\
\hline & 41-50 years & 32 & 14.3 \\
\hline & $51-60$ years & 28 & 12.5 \\
\hline \multirow[t]{2}{*}{ Sex } & Male & 1 & 0.4 \\
\hline & Female & 223 & 99.6 \\
\hline \multirow[t]{4}{*}{ Religion } & Muslim & 102 & 45.5 \\
\hline & Hindu & 118 & 52.7 \\
\hline & Christian & 3 & 1.3 \\
\hline & Buddhist & 1 & $0.4 \%$ \\
\hline \multirow[t]{2}{*}{ Marital Status } & Married & 193 & 86.2 \\
\hline & Unmarried & 31 & 13.8 \\
\hline \multirow[t]{3}{*}{ General Educational } & SSC & 113 & 50.4 \\
\hline & HSC & 105 & 46.9 \\
\hline & BA & 6 & 2.7 \\
\hline \multirow[t]{3}{*}{ Professional Educational Level } & Diploma in Nursing & 196 & 87.5 \\
\hline & BSc in Nursing & 26 & 11.6 \\
\hline & MSc in Nursing/MPH & 2 & 0.9 \\
\hline \multirow[t]{3}{*}{ Designation } & Staff Nurse & 15 & 6.7 \\
\hline & Senior Staff Nurse & 195 & 87.1 \\
\hline & Nursing Supervisor & 14 & 6.3 \\
\hline \multirow[t]{4}{*}{ Working experience } & $0-6$ months & 9 & 4.0 \\
\hline & 6-12 months & 5 & 2.2 \\
\hline & $1-5$ years & 88 & 39.3 \\
\hline & $>5$ years & 122 & 54.5 \\
\hline \multirow[t]{2}{*}{ Training on TIC } & Yes & 58 & 25.9 \\
\hline & No & 166 & 74.1 \\
\hline
\end{tabular}


Table 1 shows the Socio demographic characteristics of the respondents. Majority number 93 (41.5\%) of the respondents belonged to 31-40 years of age and others was 71(31.7\%) age 21-30 years,32(14.3\%) age41-50 years,28(12.5\%) age 51-60 years of the respondents. Most of the respondents were female 223(99.6\%) rests were male 1(.4\%). Among the respondents (224), Muslim 102(45.5\%), Hindu 118(52.7\%), Christian 3(1.3\%) and Buddhist 1(.4\%). Majority of respondents were Senior Staff Nurse195 (87.1\%), Staff Nurse were 15(6.7\%) and Nursing Supervisor $14(6.3 \%)$. Out of 224 respondent's majority of them $193(86.2 \%)$ were married and rest of them was unmarried $31(13.8 \%)$. Majority of the respondents were SSC 113(50.4\%), and rest of them were HSC 105(46.9\%), and BA 6(2.7\%). Among the respondents were Diploma in Nursing 196(87.5\%), BSc in Nursing 26(11.6\%) and rest of them were MPH $2(.9 \%)$. In working experiences, majority of them were 5 years above $122(54.5 \%)$ experience, 0-6 months $9(4.0 \%), 1-$ 5years $88(39.3 \%)$, the less common working experience 6-12 months 5(2.2\%). Among the respondent 224, training about tuberculosis infection control was 58 (25.9\%) and has no training 166 (74.1\%).

Table 2 Distribution of the respondents according to the practice about Tuberculosis infection control (TIC) (n=224)

\begin{tabular}{|c|c|c|c|}
\hline Variable's & Responses & Number & Percent \\
\hline \multirow[t]{3}{*}{ Using PPE } & Always & 30 & 13.4 \\
\hline & Sometimes & 129 & 57.6 \\
\hline & Never & 65 & 29.0 \\
\hline \multirow[t]{3}{*}{ Follow guideline } & WHO guideline & 163 & 72.8 \\
\hline & National guideline & 44 & 19.6 \\
\hline & Don't know & 17 & 7.6 \\
\hline \multirow[t]{3}{*}{$\begin{array}{l}\text { Used preparation during } \\
\text { hand washing }\end{array}$} & $\begin{array}{l}\text { Running water and liquid } \\
\text { hand wash }\end{array}$ & 112 & 50 \\
\hline & Running and soap water & 83 & 37 \\
\hline & $\begin{array}{l}\text { Antiseptic preparation for } \\
\text { hand washing }\end{array}$ & 29 & 13 \\
\hline \multirow{3}{*}{$\begin{array}{l}\text { Number of times ward } \\
\text { swept daily }\end{array}$} & Once daily & 118 & 53 \\
\hline & Twice daily & 68 & 30 \\
\hline & More than two & 38 & 17 \\
\hline
\end{tabular}

Table 2 shows the practice about TIC of the respondents. Majority of the respondents used Personal protective equipment sometimes $57.6 \%$ (129), always $13.4 \%$ (30) and never $29.0 \%$ (65). Most of the respondents were used WHO guideline $72.8 \%$ (163), National guideline $19.6 \%$ (44) and Don't know $7.6 \%$ (17). Figure 4 shows that majority of the respondents 50\% (112) used running water and liquid hand wash, rest of them $37 \%$ ( 83) used running and soap water, $13 \%$ (29) used antiseptic preparation for hand washing. Most of the respondent saw that the ward swept once daily $53 \%$ (118), and then twice daily $30 \%$ (68) and rest of them more than two $17 \%$ (38).

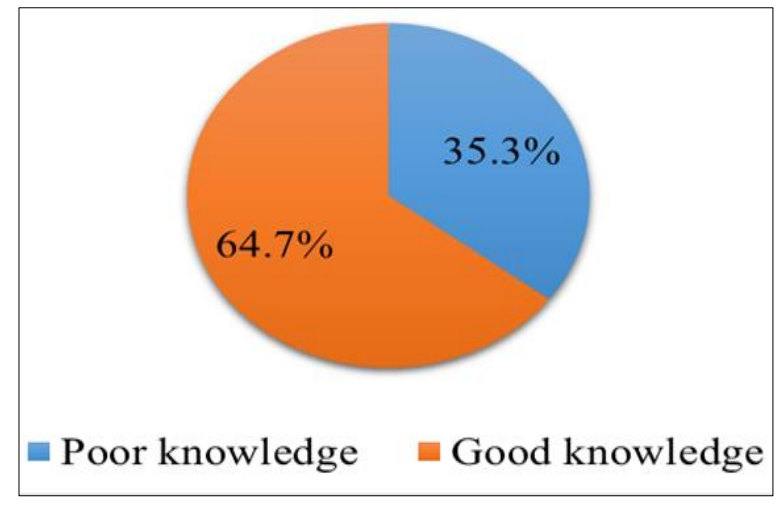

Figure 1 Distribution of the respondents according to overall knowledge about TIC ( $\mathrm{n}=224)$ 
Figure 1 shows that respondent's majority of them $64.7 \%$ (145) were good knowledge and rest of them were poor knowledge $35.3 \%$ (79).

Table 3 Relationship of the respondent's professional educational qualification and knowledge level $(n=224)$

\begin{tabular}{|c|c|c|c|c|}
\hline \multirow{2}{*}{$\begin{array}{l}\text { Professional } \\
\text { educational } \\
\text { qualification }\end{array}$} & \multicolumn{2}{|c|}{ Knowledge } & \multirow[t]{2}{*}{ Total } & Test \\
\hline & $\begin{array}{c}\text { Poor } \\
\text { knowledge }\end{array}$ & $\begin{array}{c}\text { Good } \\
\text { knowledge }\end{array}$ & & \multirow{5}{*}{$\begin{array}{l}\text { Fisher' } \\
\text { Exact } \\
\text { Test=12.554 } \\
\mathrm{p}=.002\end{array}$} \\
\hline Diploma in nursing & $62(27.68 \%)$ & $134(59.82 \%)$ & $196(87.5 \%)$ & \\
\hline B.Sc in nursing & $17(7.59 \%)$ & $9(4.01 \%)$ & $26(11.61 \%)$ & \\
\hline M.Sc in nursing/ MPH & $0(0 \%)$ & $2(0.89 \%)$ & $2(0.89 \%)$ & \\
\hline Total & $79(35.27 \%)$ & $145(64.73 \%)$ & $224(100)$ & \\
\hline
\end{tabular}

Table 3 shows that Diploma in nursing 87.5\%(196) have good knowledge 59.82\%(134) and poor knowledge $27.68 \%(62)$, B.Sc. in nursing11.61\%(26) have good knowledge 4.01\%(9) and poor knowledge 7.59\%(17), rest of them was MPHo.89\%(2) have good knowledge. There was statistically significant relationship was found between professional educational qualification and knowledge level of the respondents. (Fisher's Exact Test=12.554, $\mathrm{p}=.002$ ).

Table 4 Distribution of practice status of the respondent's observational checklist

\begin{tabular}{|c|c|c|c|c|c|c|}
\hline SL/NO & Practice item & Yes & percent & No & Percent & Total \\
\hline 1 & $\begin{array}{l}\text { The room where participant work has } \\
\text { cross ventilated window \& Door }\end{array}$ & 196 & 87.5 & 28 & 12.5 & $224(100 \%)$ \\
\hline 2 & $\begin{array}{l}\text { Using mask when approaching TB } \\
\text { suspected patient }\end{array}$ & 219 & 97.8 & 5 & 2.2 & $224(100 \%)$ \\
\hline 3 & $\begin{array}{l}\text { Frequency of an wearing N95 mask } \\
\text { when around TB patients or suspects }\end{array}$ & 34 & 15.2 & 190 & 84.8 & $224(100 \%)$ \\
\hline 4 & $\begin{array}{l}\text { Frequency of separating coughing } \\
\text { patients from other patients attending } \\
\text { hospital }\end{array}$ & 118 & 52.7 & 106 & 47.3 & $224(100 \%)$ \\
\hline 5 & $\begin{array}{l}\text { Frequently instruct coughing patients to } \\
\text { cover their mouth with tissues, } \\
\text { handkerchief or their arm when } \\
\text { coughing }\end{array}$ & 207 & 92.4 & 17 & 7.6 & $224(100 \%)$ \\
\hline 6 & $\begin{array}{l}\text { Frequently ask each patient when they } \\
\text { enter the hospital, if they are coughing }\end{array}$ & 79 & 35.3 & 145 & 64.7 & $224(100 \%)$ \\
\hline 7 & $\begin{array}{l}\text { Frequent hand wash after contact with } \\
\text { patients each and every time }\end{array}$ & 115 & 51.3 & 109 & 48.7 & $224(100 \%)$ \\
\hline 8 & $\begin{array}{l}\text { Frequently give health education \& } \\
\text { instruct about personal hygiene to the } \\
\text { patients }\end{array}$ & 61 & 27.2 & 163 & 72.8 & $224(100 \%)$ \\
\hline 9 & $\begin{array}{l}\text { Presence of Tuberculosis Infection } \\
\text { Control Guideline }\end{array}$ & 93 & 41.5 & 131 & 58.5 & $224(100 \%)$ \\
\hline
\end{tabular}

Table 4 according to observation-the room where participant work has cross ventilated window and door were well maintained, most of the respondents used normal mask and surgical mask when approaching TB suspected patient. Among 224 respondents only 34(15.2\%) used N95 mask during performing their duties. Very few of them practice 
separating coughing patents from other patients attending hospital. Most of the respondents often instructed the coughing patients to cover their mouth with tissues, handkerchief or their arm when coughing, poor practice of ask the patients if they are coughing and poorer practice of hand washing after contact with each and every time and give health.

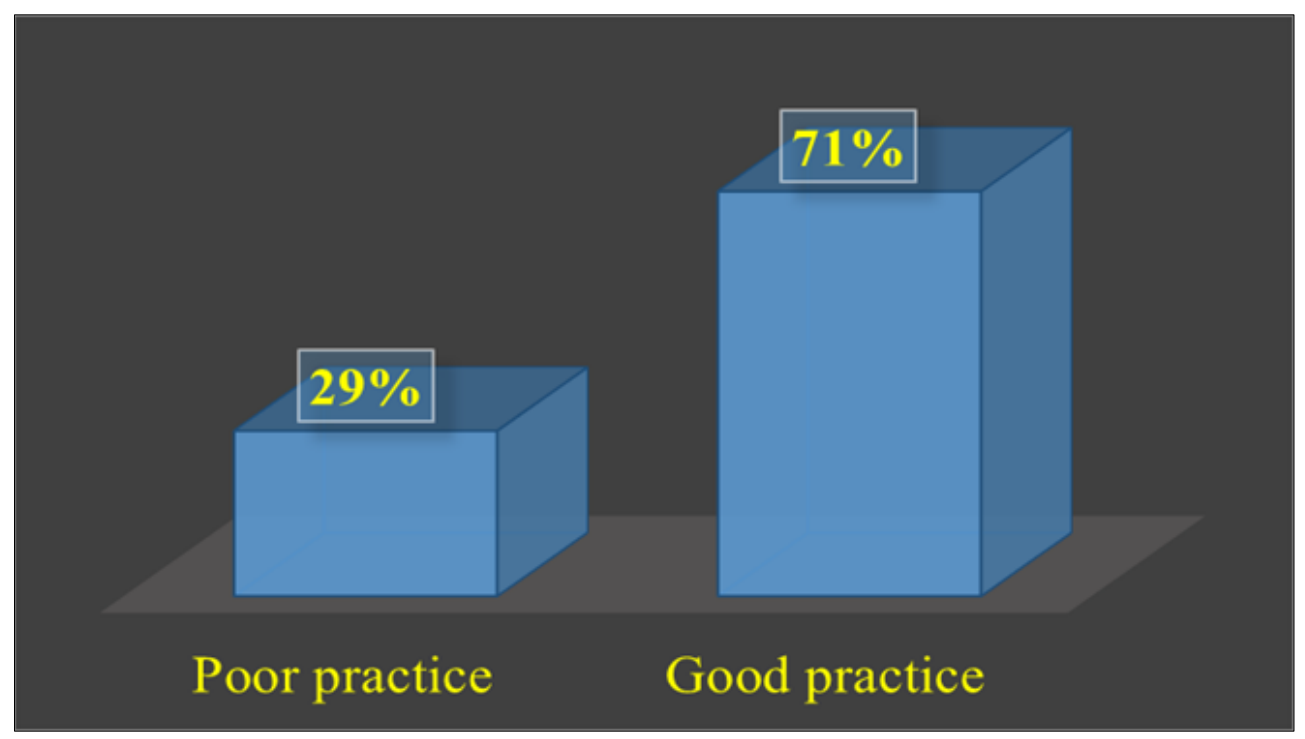

Figure 2 Distribution of the respondents according to overall practice of TIC $(n=224)$

Figure 2 shows that respondent's majority of them 71\% (159) were good practice and rest of them were poor practice $29 \%(65)$.

\section{Discussion}

Tuberculosis infection control is a combination of measures aimed at minimizing the risk of TB transmission within populations. Following the Centers for Disease Control and Prevention and World Health Organization guidelines on TB infection control, the Nigerians Federal Ministry of Health has published guidelines on TB Infection Control in HIV care settings [7]. Tuberculosis (TB) remains a major global health problem. It causes ill-health among millions of people each year and ranks as the second leading cause of death from an infectious disease worldwide, after the Human Immunodeficiency Virus (HIV). The number of TB deaths was large given that most are preventable if people can access health care for a diagnosis and the right treatment is provided [8].

TIC measures to reduce nosocomial infection-including developing an infection control plan, educating health professionals and patients, improving sputum collection practices, performing triage and evaluation of suspected TB patients in outpatient settings, reducing exposure in the laboratory [9], and employing administrative controls (early detection, isolation, and treatment of patients with TB)-have been the most effective components of TBIC programs [10].

\section{Conclusion}

This study found that knowledge and practice among nurses about tuberculosis infection control measure were good but poorly implemented of infection control guideline. There was lack of supervision and monitoring for maintaining of infection prevention of tuberculosis. By observation there was availability and less uses of personal protective equipment, lack of health information and health education provided by the nurses was poor. More TIC program should be enhanced among nurses whose knowledge and practice were poor because of most the respondents had no training on infection control. It can also be used to benchmark the evaluation of TIC interventions, especially in setting where TIC guideline have not been optimally implemented. It is recommended that training on TBIC should be provided for nurses. Education, knowledge, training about infection control and regular monitoring and supervision should needed to enhance for nurses to proper practice of prevention of tuberculosis infection. This study has provided baseline information that can be used by policy makers at various level to design interventions aimed at improving the TIC knowledge and practice of nurses. 


\section{Recommendations}

- $\quad$ This study finding suggest the following recommendations

- Education and training program using current evidence-based knowledge and practice would help improving the quality of nurses.

- Monitoring and supervision strictly maintain by the authority

- Available supply of all facilities and personal protective equipment required for applying infection control standard precautions.

- There should be regular infection control team in the hospital with achieve SOP on guideline.

\section{Compliance with ethical standards}

\section{Acknowledgments}

I express my sincere admiration and gratitude to the chairperson and all respected members of the ethical committee at the National Institute of Preventive and Social Medicine (NIPSOM) for their kind approval of the topic of my study. I express my sincere and heartfelt gratitude to Prof. Dr. Baizid Khoorshid Riaz, Director of NIPSOM and Head of the Department of Public Health \& Hospital Administration for his constructive and valuable suggestion and inspiration throughout the study period. I would like to express my sincere admiration and deepest sense of gratitude my respected supervisor, Dr. Naznin Akter Jahan, Assistant Professor Department of Nutrition and Biochemistry, NIPSOM, Mohakhali, Dhaka who have Provided thoughtful inside, expert guidance and active supervision regarding in-depth understanding of issues related to "Knowledge and Practice of Nurses Regarding Tuberculosis Infection Control in Selected Tertiary Hospital".

\section{Disclosure of conflict of interest}

None to declare.

\section{Statement of informed consent}

Informed consent was obtained from all individual participants included in the study.

\section{References}

[1] Cruz-Knight W, Blake-Gumbs L. Tuberculosis: an overview. Primary Care: Clinics in Office Practice. 1 Sep 2013; 40(3): 743-56.

[2] World Health Organization. Global tuberculosis report 2018. Geneva: WHO. 2018.

[3] Menzies D, Joshi R, Pai M. Risk of tuberculosis infection and disease associated with work in health care settings [state of the art series. Occupational lung disease in high-and low-income countries, edited by M. Chan-Yeung. Number 5 in the series]. The International Journal of Tuberculosis and Lung Disease. 1 Jun 2007; 11(6): 593-605.

[4] Malangu N, Legothoane A. Analysis of occupational infections among health care workers in Limpopo province of South Africa. Global journal of health science. Jan 2013; 5(1): 44.

[5] Centers for Disease Control and Prevention. Guidelines for preventing the transmission of mycobacterium tuberculosis in health-care settings, MMWR Recomm Rep. 2005; 54(17): 1-141.

[6] World Health Organization. Policy on TB Infection Controls in Health-Care Facilities, Congregate Settings and Households, WHO/HTM/TB.419. WHO, 20 Avenue Appia, 1211 Geneva 27, Switzerland. 2009.

[7] Njepuome N, Nwobi BC, Akpan H. The national guidelines for Tuberculosis infection control. FMOH; Abuja, Nigeria. 2008.

[8] World Health Organization. Global tuberculosis report. WHO/HTM/TB/2013.11. Paris: WHO. 2013.

[9] World Health Organization. Guidelines for the prevention of tuberculosis in health care facilities in resourcelimited settings. Geneva: WHO. 1999; 99: 269.

[10] Blumberg HM, Watkins DL, Berschling JD, Antle A, Moore P, White N, Hunter M, Green B, Ray SM, McGowan JE. Preventing the nosocomial transmission of tuberculosis. Annals of internal medicine. 1 May 1995; 122(9): 65863. 